\title{
1
}

\section{Understanding the Military Veteran}

\section{Introduction}

Key concepts in understanding and treating military and veteran patients are included in this chapter. Understanding how combat changes a person's lifestyle, the relationship of attachment to coping with loss and grief, military core values, and suicidality among the military and veteran populations are addressed. Three key questions for the intake session are discussed. Resources for understanding military language with its acronyms are provided along with a description of the influence of Stoicism on military leaders from George Washington to the present military commanders. Clinical issues such as dissociative distortions and compartmentalization are addressed for assisting the therapist in delivering effective treatment to a wide range of clinical presentations. The goal of this chapter is to enhance the EMDR therapist's understanding of the military population and how to use the understanding to achieve significant treatment results.

\section{Learning Objectives}

- Review unique aspects of the military culture such as behavioral patterns, leadership, and attachment styles.

- Identify the strengths of EMDR therapy in treating the military and veteran populations.

- Review the military's core values within each branch of service in the United States and Canada.

- Identify the leadership philosophy among military personnel such as Congressional Medal of Honor recipient Admiral James Stockdale and Marine Corps General James Mattis. 


\section{UNDERSTANDING THE MILITARY AND VETERAN CLIENT}

\section{DUTY, RESPONSIBILITY, AND AUTHORITY IN THE MILITARY}

Military culture is structured around duty, responsibility, and authority enacted by military personnel. A duty is something a servicemember must do by virtue of their assigned position. Duty has a legal or moral obligation. Service personnel are trained to perform their duties beginning with their entry-level advanced training. Duties vary for each rank. Some duties are based on rank, whereas others are determined by assigned position. For example, a salute is an outdoor exchange of greeting. It is a courtesy rendered as the senior ranking person receives the salute from the junior. There are three types of duties: specified, directed, and implied. Specified duties are outlined in the Uniform Code of Military Justice (UCMJ), field manuals, and regulations. Directed duties are designated tasks assigned by a command authority such as a sergeant of the guard or charge of quarters (CQ). Implied duties are usually individual responses assumed by the individual without written directives.

Responsibility is based on a person being accountable for what a servicemember does or fails to do. This includes the completion of one's designated duty. A cook is responsible for ensuring military personnel have food for meals; a bomb disposal expert (EOD) is responsible for assessing a potential for deactivation; and a military aviator is responsible for being fit to fly the next mission. Responsibility is held at all command levels. All servicemembers are responsible for keeping physically fit. Military leaders such as noncommissioned officers (NCOs) are responsible not only for their individual duties, but also to ensure the success of those they lead. The same is true for officers in command. Commanders also have the collective accountability for the performance of duties within their command in order to be mission ready. It is the power of leaders to direct those servicemembers to take action within their area of responsibility. General officers and Navy flag officers (admirals, vice admirals, and rear admirals) have responsibility for ensuring those units under their command are mission ready to accomplish their designated tasks.

\section{RANK HAS ITS MEANING AND PRIVILEGE}

RHIP in the military means "rank has its privilege." A common saying during the Vietnam era was "God must love Privates because there are so many of them!" In some overseas bases, a Marine has to hold the rank of sergeant or higher before they can own a vehicle. The enlisted Joes (junior ranks E-1 - E-4) catch much of the extra duties. 
Understanding the military rank structure can be important for therapists. Recently, while providing EMDR consultation, a consultee described her client as being a seaman who was avoiding engaging in his treatment. Generally defined, a seaman is a mariner or sailor. More specifically, in many navies of the world, seaman is used to designate a rank, one of the lowest ranks in the Navy. Use of the word "seaman" led me to believe the client was a young Navy enlistee with limited life experience. On further inquiry, she indicated her client was an E-9. Enlisted ranks in the U.S. military range from the lowest rank (E-1) to the highest enlisted rank (E-9). An E-9 in the U.S. Navy is a Master Chief Petty Officer, one of the most senior ranking NCOs in the service. A Navy Master Chief engaged in therapy usually means he is serious about being in the therapist's office; otherwise, he would not be seeking treatment. The perceived avoidance is more likely that of a salty NCO who has a cautious approach to evaluate the treatment options.

\section{Military Language and Acronyms}

The military uses a unique vocabulary to describe much of its equipment, concepts, and operations. Add to this unique vocabulary the ever-increasing list of acronyms, and the most seasoned servicemember can be confused by some of the language. For example, the military name for restroom is "latrine" in the U.S. Army and "head" in the Navy and Marines. An eating facility is referred to as the "mess," "mess hall," or "dining facility." Meals for consumption in the field are known as "MREs" meaning "Meals, Ready to Eat." "Stand to" is the time when combat troops living on a base arise early and position themselves around the perimeter of the base to diligently look into the darkness of early dawn watching for any moving silhouette indicating the enemy is about to attack. As the sun rises and it is clear there is no threat, the command is given to "stand down" meaning go about your regular daily routine. I frequently use these terms in working with hypervigilant servicemembers, illustrating there are times to be "on guard" and other times to "let down our guard." We are not designed to stay on guard permanently.

"Chest candy" refers to the ribbons and medals worn on a uniform. In the Air Force, an "Eagle Keeper" refers to the maintenance crew serving an F-15 fighter. A "5-sided puzzle palace" is reference to the Pentagon. "Black" on ammunition, water, or fuel indicates the resource is gone. "Ate-up" refers to a servicemember who doesn't understand regulations at all, or who follows regulations so closely they disregards the context of the situation. Military organizations also use the phonetic alphabet for clarification in communication. All U.S. and NATO (North Atlantic Treaty Organization) bases use a phonetic alphabet 
to avoid confusion with specific words. Resources with the military glossary of words are readily available online (www.military.com/join -armed-forces/glossary-of-military-acronyms.html and www.military .com/join-armed-forces/military-terms-and-jargon.html).

\section{ATTACHMENT IN THE MILITARY}

Attachment is an important component in understanding military interactions among servicemembers. An infantry soldier said to me, "I would not want my family to know this, but I am closer to my guys than I am to my own family!" This statement is common among veterans who served in combat. Living in a combat zone produces core lifeor-death survival needs. Survival arouses the basic attachment needs that exist in a person from birth. Attachment theoretically provides the framework for affect regulation, interpersonal skills, and social support responses. A person's primal survival questions include: "Who can I count on to protect me?" and "Is there someone attentive to my needs?" These statements are often expressed by the question "Who has my six?", meaning "Who is looking out for me?" Military personnel live with these questions during the carrying out of their duties. The military community provides a place where basic needs such as food and shelter are provided along with a ready-made community of persons who become responsible for the survival of each other. Relational connections become integrated with the basic needs for survival and safety. The combat environment is a place for attachment to occur among persons who depend on each other for survival. During combat, servicemembers fight for the survival of each other. Military leadership is responsible for the care of those subordinate members of the unit.

Servicemembers identify those persons whom they can count on, those who "have their six," that is, protect their back. Attachment bonds develop between an individual and those who share survival responsibilities. During intense military missions, an individual's attachment style is superseded, at least in part, by the military actions each servicemember is trained to perform. Performance during the mission defines the social acceptance of each person. Being trained in the appropriate response avoids much of the interpersonal drama that might be obvious at more normal times. The defense of the team/unit intensifies the attachment bond among members. Persons who enlisted in the military find the military structure provides an almost ideal attachment experience with its provisions of basic survival needs including physiological, safety, and a sense of belonging. The strength of attachment bonds influences the degree of interpersonal connection among members as well as the intensity of grief and survival guilt when friends are killed.

Campbell, Ryan, Wright, Devore, and Hoge (2016) describe combat attachment with its intense adrenalin-producing experiences as addic- 
tive. Attachment is enhanced as the veteran becomes addicted to the feelings of excitement or euphoria and physiological hyperarousal in connection with mission operations shared with the team. The arousal pattern becomes cyclical in reexperiencing memories of exciting adrenalin-producing events followed by times of emotional numbness, guilt, and overall feeling down. There is a social component to the adrenalin rush numerous military personnel share following a combat tour.

Journalist Sebastian Junger, co-director of the film Restrepo and author of Tribe (Junger, 2016), wrote about the alienation many veterans experience on returning from war in comparison to the bond experienced by soldiers in combat. He suggests the rate of posttraumatic stress disorder (PTSD) among military personnel is caused more by the loss of attachment bonds among servicemembers returning home than the intensity of their combat trauma. Research by Escolas et al. (2012) found attachment styles were correlated with PTSD after deployments. Once home, secure attachment styles among veterans were associated with fewer reported symptoms of PTSD. It is suggested that attachment may be associated with protection from PTSD.

The military structure with its defined organization, roles, duty responsibilities, and boundaries removes much ambiguity to the sense of belonging. Military personnel wear badges and patches to uniform clothing indicating they belong. Strong cohesion is developed within units who endure both intensive training and danger. Unit cohesion has been correlated with less mental health pathology (Junger, 2016).

Anniversary dates and occasions when members of the unit were killed become embedded in servicemembers' personal awareness. Wrist bracelets and tattoos memorialize the life of persons lost in combat noting the date the loss happened. The strength of attachment bonds correlate with the severity of grief at the time of loss. Many veterans carry unresolved grief due to the loss of their military friends. Guilt and anger are often components of grief. Unresolved grief is often managed with avoidance until the anniversary dates of their death. Frequently, on anniversary dates veterans review their photos and watch YouTube videos of combat operations and contact their buddies to discuss those times together. Family members and therapists learn to prepare for these dates while assisting the veteran to address the loss in healthy ways. Unresolved grief is one of the most common psychological wounds among veterans. If left unresolved, the grief becomes normalized as part of the servicemember's life experience. The wounds of unresolved grief can be numerous among our servicemembers. Therapists treating these populations learn to identify losses in the person's life, including anniversary dates when friends were killed, as part of the client's initial history-taking phase. Persons medically retired may grieve over the loss of identity in a warrior culture, while struggling with physical and psychological limitations. 
Members of the military population learn of the culture during basic training. The military environment influences every servicemember to: (a) take initiative (lead, follow, or get out of the way!); (b) be responsible; (c) be competitive in pushing oneself to the limit; (d) place teamworkbeforeindividualneeds; (e)maintainmilitarybearing; (f) pay attention to detail; (g) maintain uniformity; (h) remember that individual mistakes cost everyone; (i) be ready for quick action; (j) note that punishment for screwing up may include the entire team; (k) obey (follow orders); and (l) learn to manage caustic comments.

Combat veterans exhibit common survival characteristics. When entering a room, many prefer to sit facing the door with their back to the wall. A number of infantry soldiers describe their plan to respond to any threat before they are seated in a room. Using risk assessment, they assess the risk level and have a response plan in case they are attacked. In office waiting rooms and public places, veterans monitor the activities continually evaluating the threat level-always with a plan in case an attack happens.

Military bearing describes how a servicemember carries themselves, straight and erect, as well as the briskness of the walk. Servicemembers are taught in basic training (boot camp for Marines) to always walk at a brisk pace as if you have somewhere to go. Present yourself as a person on a mission. In fact, basic training usually begins with the recruit having to run everywhere when they are outdoors. The pace of walking is ingrained in everyone who has served in the military. Years later, while walking with a nonmilitary partner, the partner notices the veteran does not slow down when walking, even when accompanying a partner to social engagements. Veterans, when aware, often work to slow down, but find themselves spontaneously walking faster again.

Present awareness and risk assessment of the current situation is a part of military life. The more threatening a veteran perceives the situation, the more vigilant or hypervigilant their response will be. Some persons regulate the anxiety of exposure in public places by monitoring their social activities. Feeling in control of the situation eases anxiety. If the effort to monitor their activity becomes too challenging, the veteran will likely socially withdraw as a means of controlling the environment. This means avoiding unnecessary shopping or shopping in the early hours of the morning when the least number of shoppers are present. Avoiding shopping malls or supermarkets is a strategy for narrowing the circle of activity in order to maintain security. If the amount of stimuli lessens with social withdrawal, the servicemember feels more in control of the situation. In one case a senior NCO, now living back in the states but suffering with severe psychological wounds due to multiple combat deployments, refused to leave his apartment to buy groceries. Instead, he ordered diet meals from Jenny Craig, which were delivered to his apartment. The NCO felt secure enough to function 
in his duties while at his assignment on base but not in open shopping areas. Shopping areas reminded him of the danger of open marketplaces where suicide bombers would kill people. His perceived risk in a public marketplace was more than he was willing to endure even when back home. He was easily triggered when seeing someone whose clothes reminded him of his combat environment.

Veterans, especially persons with stress-related difficulties, prefer routine activities rather than novel situations since new situations require additional psychological strain in conducting risk assessment. Seeking treatment can be a stressful experience. Meeting a new person such as a receptionist and therapist as well as monitoring the threat level in a strange environment, such as a waiting room, can be fatiguing for a person suffering with complex trauma. The threat level of a waiting room is further enhanced with the awareness that veterans have killed themselves at Department of Veterans Affairs facilities, a place where veterans seek help. Predictable routines reduce stress; the possibility of unpredictable events happening adds to the stress.

Military personnel tend to arrive for their appointment early. They are taught that arriving at the time of the appointment means they are late; therefore, they need to arrive 15 to 20 minutes early. There have been many couples who argue when the partner did not understand this rule and prepared to arrive just at the time of the appointment. Couple spats also occur when the soldier places the head gear (cap) and gloves at a place only to find they have been moved the following morning when it is time to leave for morning formation. The soldier reacts as if the situation is a matter of life or death because down range, in a combat environment, time can determine life or death. Taking unnecessary time to hunt for equipment can be a matter of life and death down range when under attack.

Veterans, back from combat, express few emotions, except for anger. Warriors on combat missions consider anger as a gift. It allows the warrior to feel empowered. Other emotions get in the way of this functioning, so they are turned down during deployments. In relationships back home, the partner may begin to question if they are still loved based on the servicemember's lack of emotional expression. The servicemember, oblivious to the emotional distancing, continues to maintain the same response exhibited during the past year of deployment. This is an attempt to maintain a sense of normalcy. The stressors associated with the need to adapt and adjust now that the servicemember is home frequently contribute to the military client's wish to be back over there, a place where life did not require so much adjustment. "It was easier there!"

Returning home requires learning another routine, adjusting to time differences, and remembering to be attentive to other people's feelings. When faced with life or death every day, the concept of some- 
one getting their feelings hurt may seem pathetic to the warrior! It is too far up Maslow's hierarchy of needs to contend with in combat. You can't just say something straightforward any longer because those you care about will get their feelings hurt-then you have to expend more time and effort making amends! This can be exhausting for the servicemember and family members. The degree of stress from combat missions determines how stressful returning home can be for the servicemember. For some persons, returning home is a well sought dream for returning to loved ones. Others, particularly those with psychological wounds from repetitive exposure to combat, find daily living back home can be emotionally challenging. Many servicemembers believe the daily routine in combat was easier. An infantry sergeant told me, "The Army taught me my job in the infantry was to put as many rounds as possible down range. Now that I am home, I want to have some positive conversation with my wife. We sit down to talk and then, the first thing we disagree on, I lay down overwhelming suppressing fire verbally. Next thing I know, she is mad, won't speak to me and I am left questioning, "what did I just do?'”

\section{Understanding Those Who Run TOWARd DANGer}

"When we go into battle, I will be the first one to set foot on the field, and I will be the last to step off. And I will leave no one behind. Dead or alive, we will come home together. So help me God."

\section{- Lt. Co. Hal Moore, August 1965, Fort Benning, Georgia}

This statement was made by then Lieutenant Colonel Hal Moore when addressing his soldiers at Fort Benning, Georgia, before deploying to Vietnam. Military personnel and first responders are sometimes identified as those who run toward danger rather than away from it! It is a person's core values and mental focusing that allows them to accomplish the mission while managing emotions. They focuses on the assigned duty while ignoring emotions that could interfere with the mission. The mission comes first! Thoughts or feelings are not as important as accomplishing the mission. This approach allowed firefighters to run into New York City's collapsing twin towers on 9-11. It was also present in military officers such as Lt. Colonel Moore, battalion commander of the 7th Cavalry, who would later lead his troops in an extensive battle at la Drang, Vietnam. The same core values continue to guide servicemembers today. Sky Soldiers with the 173rd Airborne Brigade had the mission of maintaining a forward operating base (FOB) in the Korengal Valley of Afghanistan, a place considered one of the deadliest in Afghanistan. They held their ground in spite of being daily rocketed, mortared, and shot at throughout their entire mission. Numerous service personnel from all branches of the military confront these challenges routinely. 
Providing effective treatment to military and veteran populations provides therapists the opportunity to learn about the uniqueness of their clientele. Establishing rapport is multidirectional; the client in your office is attempting to understand you and your work environment while at the same time you are working to develop a therapeutic relationship. It is important to recognize how difficult it is for your client to be in your office. Your office is familiar terrain to you; however, it is unchartered territory to your client. Unfamiliar areas are considered a threat to one's well-being until proven otherwise. Negotiating the security of your office is important to your client.

\section{Military Core Values}

Understanding what molds the character and influences the essence of the military women and men in your office is an important part of your clinical preparation. The military culture molds character. This process begins for military personnel at the induction center as every new inductee takes the Oath of Enlistment. All U.S. military personnel swear to support and defend the Constitution. The Constitution is the source of the military's authority as represented by the American people, those duly elected and appointed representatives, and the officers in command, as well as other personnel entrusted with executing orders. The first oath of enlistment was established in 1775. Today's military oath of enlistment was established on October 5, 1962, which replaced some of the original wording contained in the 1775 and 1780 editions. Listed here is the oath of office for enlisted military servicemembers:

I, do solemnly swear (or affirm) that I will support or defend the Constitution of the United States against all enemies, foreign and domestic; that I will bear true faith and allegiance to the same; and that I will obey the orders of the President of the United States and the orders of the officers appointed over me, according to regulations and the Uniform Code of Military Justice. So help me God.

\section{U.S. Army Center of Military History (N.D.)}

Both enlisted and officer oaths require the person to swear (or affirm) they will defend the Constitution of the United States, to adhere faith and allegiance to it, and obey the orders of the president and superior officers in accordance with the UCMJ. This swearing in occurs before the person begins basic training. Basic training immerses a person into a military community where physical development, introductory knowledge of military traditions and culture, and military skill development are provided.

Military servicemembers are held to high standards. The military culture is based on tradition, ethos, values, and the structure and leadership of the military organization. Subcultures represented by the various branches 
of service evolve from national goals. Each branch of the military has its own history, rules, regulations, operating procedures, and perspectives.

Ethos is the spirit or national character from which values emerge. For example, the ethos of the U.S. Army is identified by the following statements: (a) I will always place the mission first; (b) I will never accept defeat; (c) I will never quit; and (d) I will never leave a fallen comrade (U.S. Army, n.d.-b).

On an individual level, core values provide the structure for servicemembers to move into action, while the mission requirement fuels the motivation, and mental processing presents the means to accomplish the mission. Those same values establish a person's priority both on duty and off duty. Priorities influence the use of a person's time, what they do, the interaction with other persons with whom they spend their time, and how they define the relationships. Values clarify what is acceptable and expected for individuals and those units they serve. Later in life, when a person reviews their military service, they use the same values to evaluate their service. The servicemember becomes acculturated to the military values as they are lived 24/7 in the military environment. Servicemembers live and breathe the values. Common guidance and unit cohesion is integrated into the entire unit as its members subscribe to those core values.

Each branch of the military has its own list of core values (Table 1.1). The values provide an organizational structure in the training and de-

\section{TABLE 1.1 Core Values: Branches of Military Service in the United States and Canada}

\begin{tabular}{|c|c|c|c|c|}
\hline U.S. Army & $\begin{array}{l}\text { U.S. Navy/ } \\
\text { U.S. Marines }\end{array}$ & $\begin{array}{l}\text { U.S. Coast } \\
\text { Guard }\end{array}$ & U.S. Air Force & Canadian Forces \\
\hline $\begin{array}{l}\text { - Loyalty } \\
\text { - Duty } \\
\text { - Respect } \\
\text { - Selfless } \\
\text { service } \\
\text { - Honor } \\
\text { - Integrity } \\
\text { - Personal } \\
\text { courage }\end{array}$ & $\begin{array}{l}\text { - Honor } \\
\text { - Courage } \\
\text { - Commitment }\end{array}$ & $\begin{array}{l}\text { - Honor } \\
\text { - Respect } \\
\text { - Devotion } \\
\text { to duty }\end{array}$ & $\begin{array}{l}\text { - Integrity } \\
\text { first } \\
\text { - Service } \\
\text { before self } \\
\text { - Excellence } \\
\text { in all we } \\
\text { do }\end{array}$ & $\begin{array}{l}\text { - Integrity } \\
\text { - Loyalty } \\
\text { - Courage } \\
\text { - Stewardship } \\
\text { - Excellence }\end{array}$ \\
\hline
\end{tabular}

Sources: Department of National Defence and Canadian Forces. (2012). Code of values and ethics. Retrieved from http://www.forces.gc.ca/assets/FORCES_Internet/docs/en/about/code-eng.pdf; U.S. Air Force. (n.d.). Air Force core values. Retrieved from https://www.airforcemomsbmt.org/ AirForceCoreValues.htm; U.S. Army. (n.d.-a). Army core values. Retrieved from https://www .army.mil/values; U.S. Navy. (2009). U.S. Navy core values. Retrieved from https://www.navy.mil/ navydata/nav_legacy.asp?id=193; U.S. Coast Guard. (n.d.). "Introduction". Retrieved from https:// www.gocoastguard.com/family-and-friends/the-helmsman/introduction. 
velopment of its members. While the EMDR therapist interacts with the client's clinical presentation, much of the unspoken attitudes and expectations are driven by the core values taught and lived within the military culture. Most veterans judge themselves by the standards of the core values.

The task of training hundreds of thousands of military personnel to perform their duties in a specific manner begins with entry-level training including character development along with combat skill development. Each branch of the military, from every nation, has its own standards and core values. For example, the U.S. Army lists seven core values. The U.S. Navy, Marines, Air Force, and Coast Guard each embrace three core values. There are five core values listed by the Canadian armed forces. Entry-level basic training introduces military personnel to the core values of their service branch. Those values assist in establishing priorities and accomplishing effective decision-making, mission readiness, and performance standards. Later, during periods of transition, those ethical guidelines represented by the core values are used to provide guidance.

Guidelines provide direction to military personnel for managing situations within their military experience. They also provide a tension between the ideal and the daily challenge of life amidst the chaos of combat. The Armed Forces Code of Conduct (U.S. Government Printing Office, 1958) was developed following the Korean conflict when the Pentagon learned that as many as three out of five American prisoners of war (POWs) may have cooperated with the enemy. Later, during the Vietnam War, POWs such as James Stockdale, a Navy pilot shot down and held captive in the Hanoi Hilton POW camp for 7 years, described how aspects of the Code of Conduct were challenging to maintain where he was imprisoned. The directive to only provide "name, rank, and serial number" was difficult for many prisoners who were tortured at the Hanoi Hilton prison camp. The enemy used forced confessions against the American war effort. Jeremiah Denton, another naval aviator held captive for more than 7 years in North Vietnam, was forced to make anti-American statements all the while using the blinking of his eyes to send a Morse Code message "torture." POWs were caught between the ideal values of their military training and coping with some of the most inhumanly inflicted pain imposed by their captors. Military core values have been emphasized, particularly following the moral failures of My Lai during the Vietnam War and the moral crisis at Abu Ghraib prison during Operation Iraqi Freedom (OIF). The war policy during OIF led to the "revolt of the generals" when more than 20 American generals defied military tradition to publicly criticize the administration's policy in the conducting of the war in Iraq (Sauer, 2007). Such moral crises within the military have historically required emphasizing the core values within the military branches of service. The emphasis on core values mediates the ethical and moral failures during the chaos of war. Publications such as A Brief History of Army Values (Center for the Army Profession and Ethic, 2018) highlight the variations in recognition of the 
military service branches' core values. The teaching of core values has become an important part of guiding the military force.

Core values maintain the moral and ethical climates of the armed forces. Understanding these values assists psychotherapists in understanding the military culture of their military and veteran clients.

The Canadian Armed Forces' Code of Values and Ethics, published by the Department of National Defense (DND) and Canadian Forces (CF), outlines three ethical principles for the CF: (a) Respect the dignity of all persons; (b) serve Canada before self; and (c) obey and support lawful authority.

The values and behaviors expected of members of the CF and DND include (a) integrity, (b) loyalty, (c) courage, (d) stewardship, and (e) excellence. Detailed information regarding the ethical principles and code of values is published in Code of Values and Ethics available online (DND and CF, 2012). Members of the CF who fail to comply with the ethical principles, values or expected behavior, or other policies outlined in the Defense Administrative Orders and Directives (DAOD) can be subject to: change of duty; release or other administrative action; or disciplinary action under the Canadian National Defense Act (Department of National Defence and Canadian Forces, 2012).

These values represent the heart and soul of every servicemember even when they are so subtle the therapist has to search to find them. Understanding the values, along with the ability to incorporate them, has the ability to strengthen the therapeutic relationship while motivating the treatment process.

\section{STOICISM IN THE MILITARY CULTURE}

Professor Nancy Sherman, a moral philosopher with past teaching assignments at the U.S. Naval Academy, called Stoicism "the philosophy behind the warrior mind" (Sherman, 2005, p. 12). Understanding the thinking behind the warrior mind is helpful in treating the military population. Founded by the Greek philosopher Zeno of Citium in the third century BCE, Stoics came to represent a philosophical approach to life which provided followers a practical sense of self-command, self-reliance, resilience, and moral autonomy while encouraging cardinal virtues such as temperance, wisdom, and courage (Sellars, 2006). These qualities are attractive to many military personnel. Its teachings have influenced leaders ranging from the Roman emperor Marcus Aurelius and Fredrick the Great to today's military leaders.

George Washington was a student of the Stoic philosopher Cato the Younger. By the time Washington wrote his farewell address, he embedded several quotations from Cato into his speech (Stockdale, 1993). During the early development of Washington's Continental Army, Prussian officer Friedrich Wilhelm Rudolf Gerhard August Freiherr von Steuben 
arrived at the Valley Forge encampment to begin training soldiers in close-order drill. His strict training and discipline instilled new confidence and discipline in the demoralized army. The philosophical ideas and military theories of Fredrick the Great and his army were modeled to the fledgling Continental Army of the United States by von Steuben. Since von Steuben did not speak English, his manual of drill was written in French and translated into English by Alexander Hamilton and Nathanael Greene. The Prussian drills outlined in the manual provided organization structure as well as guidelines in executing a standard of living. Under von Steuben, Washington's shoeless soldiers practiced battle drills of firing and reloading their weapons until it became second nature, what we know today as muscle memory (von Steuben, 2018; Lockhart, 2008). The military successes learned under the Stoic king Fredrick the Great were taught to young America's Continental Army.

Both Fredrick the Great and Marine general James Mattis were known to carry copies of Marcus Aurelius' Meditations (Duncan, 2017) with them during military operations. Marine General James Mattis, the former U.S. Secretary of Defense, immersed himself in the philosophy of Marcus Aurelius with regular readings in the Meditations (Ricks, 2017). Like Fredrick the Great, General Mattis was known to carry a copy of Meditations with him on all his deployments including carrying it while leading Marines into battle in Iraq during OIF (Poser, 2018; Ricks, 2017). Even in the first nights of the military's push into Iraq, at the beginning of OIF in 2003, the general was known to clear his mind during a 4-hour rest break by reading from Marcus Aurelius' Meditations. Those who spent time with General Mattis learned he was fond of the writings of Shakespeare, Aurelius' Meditations, the Prussian military theorist Carl von Clausewitz, and the Chinese military strategist Sun Tzu (Dilanian, 2010). The Meditations was listed in General Mattis' recommended reading for leaders (Sicard, 2017).

Medal of Honor recipient James Stockdale, a U.S. Navy pilot shot down over North Vietnam and held prisoner in Hanoi for over 7 years, gave credit to the Stoic philosopher Epictetus' Enchiridion for helping him survive his prison torture 15 times, with 4 years of placement in solitary confinement, and being in leg irons for 2 years. Later promoted to Navy vice admiral and recognized as one of the Navy's most highly decorated officers in history, Stockdale recalled thinking, "I'm leaving the world of technology and entering the world of Epictetus" (Stockdale, 1995, p. 7) as his aircraft was shot down and he parachuted to a North Vietnamese village where he was severely beaten and taken prisoner. Stockdale credited Epictetus' teachings in Enchiridion for his survival as a POW.

Stockdale identified with Epictetus as he was placed in leg irons as a POW similar to Epictetus suffering with a disabled leg. While Epictetus wrote nothing, his assistant Arria recorded "Sickness is a hindrance to the body, but not to your ability to choose, unless that is your choice. Lame- 
ness is a hindrance to the leg, but not to your ability to choose. Say this to yourself regarding everything that happens, then you will see such obstacles as hindrances to something else, but not to yourself" (Stockdale, 1993).

The basic teachings of Stoicism that influence military culture include:

- Stoicism teaches a person to recognize what they can change and what they have no control over.

- Stoicism emphasizes the situation is not the problem but a person's judgment of the situation.

- Stoicism teaches concentration on what a person can control. It is referred to as the "cultivation of the "inner citadel' of the soul."

- The early Stoics took a hard line on emotions while later Stoics took a more moderate recognition of them (Farnsworth, 2018). Stoics do not reject emotions but whether passions interfere with good judgment. Distinguishing the difference between emotions and passions, the Stoics view the issue as whether emotions unseat reason. Do they blur the perspective leading the person to make misjudgments? Though a skeptic, Seneca did not dismiss emotions if they were controlled by reason. He did consider anger to be a blight on the human race.

- Fear was viewed as a feeling which could sometimes interfere with reason and judgment. Fear is viewed as making situations worse by interfering with our judgment and causing us to think and do foolish and cowardly things. It spoils the pleasure of the moment. From the Stoic perspective, fears are opinions about what is yet to come.

- Stoics consider overcoming the fear of death important. Death is an inevitable event along the continuum of life. What we must overcome is not death but the way we think about it (Seneca, 2004, Epistles, 82.15-16). Freedom from the fear of death is considered a central goal by many Stoics.

- Grief was viewed by Seneca as an unavoidable response to loss. He felt it natural and appropriate to have grief feelings for a while, then reason with them. The Stoic believed it was better to reason with feelings of grief than avoid them or distract oneself (Seneca, 2015, Consolation to Helvia, 16.1). Emotions born of grief were seen as ungovernable.

- Stoics seek to avoid adversity like anyone else would do. Adversity is a fact of life-it comes regardless. The goal is to view adversity correctly so a person's peace of mind would not be destroyed by its arrival.

Military personnel exhibit characteristics that are sometimes described as being Stoic. In general, military lifestyles often imply a per- 
son to be self-contained, downplay emotions, and focus on doing one's duty. Such characteristics are integrated into the military lifestyle of most militaries worldwide. Beyond this generic philosophical description of military characteristics, it is recognized that military leaders have publicly endorsed Stoicism as being recommended reading for officers (General James Mattis) as well as teaching resiliency for POWs (James Stockdale) and soldiers in combat (Peter Ryan). The philosophy offers guidelines to military personnel regarding how to maintain a keen perspective on what matters even in the heat of battle, how to handle emotions and passions, and how to be the master of one's own actions.

It is suggested the philosophy of Stoicism can empower a person to be more resilient and at peace with themselves (Nauvall, 2019.). Stoicism teaches a person to recognize a sense of dignity even when stripped of most resources in their experience as demonstrated by the imprisonment of POWs such as James Stockdale. The external environment does not control a person's sense of well-being. It is mind over matter as the soldier cannot control the situation, but the soldier can control their response to the situation. The philosophy reduces the sense of vulnerability while endorsing a person's robust will to succeed. It's the "cando" attitude with the ability to "suck it up and drive on" attitude that is embraced by the warrior. McMaster, retired U.S. Army general and former National Security Advisor, suggested the development of Stoiclike resilience and fortitude for self-control can offer significant value in reducing combat stress (McMaster, 2008). The appeal of Stoic philosophy among military leaders can be evidenced in the basic teachings which, when applied to military missions, assist military personnel in maintaining a clear focus on areas they can influence.

\section{CLINICAL ISSUES FOR UNDERSTANDING THE VETERAN}

\section{COMPARTMENTALIZATION AND SURVIVAL ON THE BATTLEFIELD}

Compartmentalization is a psychological coping strategy, a dissociative response to manage mental discomfort and anxiety created by a person's conflicting internal views. It allows conflicting views to coexist by inhibiting their acknowledgment and interaction. A warrior engaged in combat cannot allow himself to recall tender moments with his children; such a mental process would impede his focus on the combat mission. Memories of times with his children are reserved for times when he has completed his duty for the day/night and feels safe enough to allow such thoughts. Even then, tender thoughts of loved ones back home can become depressing, so the warrior deals with the duality of fam- 
ily memories versus current reality of war by compartmentalizing those memories.

A combat veteran sat in my office agonizing over the dichotomy he felt after serving six combat deployments now that he is back in the world. When discussing the effects of combat on his life he speaks of the guilt he feels. "It is like trying to swallow glass," he says. He is a warrior whose past 12 years have been in a combat zone or preparing to go back to one. His only self-affirmation is describing his survival skills in combat. A week before he was at his local bank waiting to conduct business with the branch manager. After waiting a few minutes. watching her shuffle papers through the glass partition to her office, he impulsively walked into her office with intense anger, dropping Fbombs and accusing her of ignoring him as a customer. "I knew I had made a mistake as soon as I opened my mouth, but I could not stop or withdraw the words coming out of my mouth," the veteran stated. Describing his dual life he said, "The person I let people see - the 'Hi! How are you?' is not who I am. Who I am they don't want to know. They would be afraid of that person!"

Military personnel are required to manage very dichotomous life experiences. The life they live during a combat deployment is very different than the social life back home. Risk assessment and situational awareness are ongoing processes during deployment. Lifethreatening experiences are always possibilities. When asked when he felt safe during deployment, a 12-year veteran replied "Never!" The reality of death is apparent, yet personnel learn to avoid focusing on that reality. Combat operations with close-call, near-death experiences are managed, so they are not held in the forefront of mental focus. This is accomplished through compartmentalization.

Historically, compartmentalization, referring to veterans being trapped in traumatized memories, has been recognized among combat veterans since the post-Vietnam era. Different terms have been used to describe the parts of personality structure in compartmentalization. The warrior persona was referred to as "Survivor mode" in contrast to "normal personality functioning" by Figley (1978). A decade later, Laufer (1988) called the components of compartmentalization the "war self" in comparison to an "adaptive self." The Structural Dissociation model (van der Hart, Nijenhuis, \& Steele, 2006), building on the 1940 work of Charles Myers, identified the civilized, socially interactive part as the Apparently Normal Part (ANP) of self and the reactive survivor part as the emotional part (EP). These compartmentalized parts sometimes develop during childhood; at other times, compartmentalization develops during adulthood due to repetitive, life-threatening events of war. Social and psychological adjustments between life in the war zone and the routines back home can create significant adjustment problems for military personnel, similar to the veteran described previously. 
When the adjustments are challenging, the servicemember sometimes longs to be back in the combat area "where things are routine."

\section{THREE MOST IMPORTANT QUESTIONS IN THE INITIAL SESSION}

Clients who experience a lack of control in their life describe feeling more vulnerability. Emotionally they need to experience additional security. The therapist can address this important issue early in the initial session by asking the client, "What do you need to feel secure in this room?" Sometimes the client wishes to have the window blinds open to monitor the outside or adjust the lighting in the room. The question conveys to the client that the therapist is aware of his needs and attentive to addressing them. This question provides the building block for developing trust and rapport in the therapeutic relationship.

The second important question in the first session is, "What do you want to change as a result of being here?" The client's answer to this question helps develop the treatment goal. This is what brings the client in for treatment. Prior to my learning EMDR therapy, I would ask the client a similar question, "How will you know when your treatment is finished?" The EMDR treatment plan is developed around the client's reason for seeking treatment. Clients are more motivated to keep their appointment and invest in its outcome when they know each session is directly connected to their reason for seeking therapy.

A third question, as a follow-up to the previous question, also asked in the initial session is "Would it be okay to get over this?" This question asks about the client's motivation for treatment as well as identifying any potential secondary gain issues. On one occasion, a soldier answered me by stating she was going through a compensatory evaluation and wished to delay her treatment until she completed her evaluation. EMDR therapy will only accomplish what the client wants done (as a treatment goal). It would have been a waste of time to have treated her before she was ready for change.

\section{DISTORTED PERCEPTIONS}

The more severe the pathology in your client, the greater the perceptual distortions the client has toward you. Learning of the dissociative experiences among military and veteran populations has taught me that many clients view me through their distorted lens. While I view myself one way, the client sees me based on their own experiences. Persons who view the world as a threat are likely to view their therapist as a potential threat in some manner. Reasons for distrust can sometimes be stronger than trust. Thus, the previous question, "What do you need to feel secure in this room?" is an important question, 
especially among persons with dissociative experiences who feel unable to control their own responses to being triggered. Additionally, inquiring about the success of other previous treatments is important. Clients report that the consistency of previous treatment programs has varied. While many dedicated psychotherapists work to provide effective treatment, the continuity of treatment is not always ideal. Warriors report having previously been treated at facilities where appointments were cancelled by the clinic at the last minute or met with a different psychiatrist or psychotherapist each session; these actions are likely to make clients unsure of the integrity of their treatment. Servicemembers who were previously treated with appointments 1 and 2 months apart reach the conclusion that what is offered is not effective or they are not important enough to be treated effectively. If they were previously treated unsuccessfully at other facilities, their trust and hope in your services is likely to be guarded. Inadequate treatment at other facilities diminished the client's hope in ever being effectively treated. Your sincerity, authenticity, and clinical skills will likely be viewed with uncertainty until the client experiences the benefits of your work as an EMDR therapist.

\section{WHEN SUICIDE IS ALWAYS AN OPTION}

It is always important to check with your client regarding any suicidality. Specifically, do they have thoughts, a plan, and the means to complete the plan? If so, immediate action is needed to get the client the help they need. Veterans living with both chronic physical and psychological pain, who are desensitized to dying, and sometimes view death as a relief, a condition needing intervention as early as possible. The timing of intervention has changed in the past decades. Some veterans today will not agree to a no-harm contract, yet they need intervention. A veteran who had just been discharged from an inpatient hospital program for his third suicide attempt stated to me, "If you ask me to promise not to kill myself, I can't promise. For me, suicide is always an option!" Many military personnel with extensive exposure to combat-related deaths seem to have become desensitized to death. Some veterans report the thoughts of death provide a sense of relief, at least at times when they suffer with physical and psychological pain. Past directions of getting a no-harm contract from the client before they can be treated does not work with some members of this population. Rather, ensuring the client has adequate support networks and is open to developing hope for the future may be the best possible context to begin treatment. For example, the previously listed veteran said to me at the end of his initial session, "I don't want you to give up hope on me doc!" I replied, "I won't give up hope on you if you do not give up hope 
on me." He replied "Roger that!" and we proceeded with the treatment. His treatment was successful, and he is now actively engaged in community activities with his family. Hopelessness has been correlated with suicide (Beck, Kovacs, \& Weissman, 1976; Beck, Brown, Berchick, Stewart, \& Steer, 2006.). Effective treatment provided in a timely manner builds hope.

\section{CONCLUSION}

The information in this chapter provides a gateway for learning about the uniqueness of the military environment, including its language, structure, and operations. It is a culture with a basic military language and the continual development of new acronyms. No one knows all the military acronyms. Instead, we learn the language we need to know for the clients we treat. Our clients teach us. Every military client has their own experience, their own history. If you are unfamiliar with the military, I encourage you to ask your client when there is something you don't understand. Persons who have a familiarity with this population are likely to find the material offered in this chapter a description of a family, sometimes challenging, at times affirming-with many memories representing a part of their life. The most difficult times are recalled with appreciation. Asking a client about their unique experiences can be empowering for the client and builds stronger bonds. This information sets the groundwork for understanding your military client through all phases of EMDR therapy.

\section{DISCUSSION POINTS}

1. In what ways does attachment influence a servicemember's ability to self-regulate?

2. How does attachment influence a person's sense of loss?

3. Is there a core value that stands out to you as being one of the most important?

4. What core value influences a person doing what they are expected to do?

5. Why is Stoicism appealing to some military leaders?

6. What key questions are suggested for use in the initial session?

7. Is compartmentalization healthy?

8. When can you treat a veteran who says "Suicide is always an option?"

\section{REFERENCES}

Beck, A., Kovacs, M., \& Weissman, A. (1976). Hopelessness and suicide behavior: An overview. Journal of the American Medical Association, 234(11), 1146-1149. 
Beck, A., Brown, G., Berchick, R. Stewart, B., \& Steer, R. (2006). Relationship between hopelessness and ultimate suicide: A replication with psychiatric outpatients. Focus on Psychiatry, 4(2), 291-296.

Campbell, M., Ryan, M., Wright, D., Devore, M., \& Hoge, C. (2016). Postdeployment PTSD and addictive combat attachment behaviors in U.S. military service members. American Journal of Psychiatry, 173, 1171-1176. doi:10.1176/ appi.ajp.2015.1501297

Center for the Army Profession and Ethic. (2018). A brief history of the army values. Retrieved from https://caccapl.blob.core.usgovcloudapi.net/web/ character-development-project/repository/a-brief-history-of-the-army -values.pdf

Department of National Defence and Canadian Forces. (2012). Code of values and ethics. Retrieved from http://www.forces.gc.ca/assets/FORCES _Internet/docs/en/about/code-eng.pdf

Dilanian, K. (2010, July 8). Marines' Mattis to take over Central Command. The Seattle Times. Retrieved from https://www.seattletimes.com/ nation-world/marines-mattis-to-take-over-central-command

Duncan, A. (2017). Stoic philosophy for military leaders. Retrieved from https://medium.com/@alex.duncan/stoic-philosophy-for-military -leaders-baf3b8d56a90

Escolas, S., Arata-Maiers, R., Hildebrandt, E., Maiers, A., Mason, S., \& Baker, M. (2012). The impact of attachment style on posttraumatic stress disorder symptoms in postdeployed military members. U.S. Army Medical Department Journal, 54-61.

Farnsworth, W. (2018). The practicing Stoic: A philosophical user's manual. Jaffrey, NH: David R. Godine Publisher.

Figley, C. (1978). Stress disorders among Vietnam veterans: Theory, research. New York, NY: Brunner-Routledge.

Junger, S. (2016). Tribe: On homecoming and belonging. New York, NY: Hachette Book Group.

Laufer, R. (1988). The serial self: War trauma, identity, and adult development. In J. Wilson, Z. Harel, \& B. Kahana (Eds.), Human adaptation to extreme stress: From the Holocaust to Vietnam (pp. 33-54). New York, NY: Springer.

Lockhart, Pl. (2008). The drillmaster of Valley Forge: The Baron de Steuben and the making of the American Army. New York, NY: Harper Collins.

McMaster, H. (2008, August-September). Survival. Ancient lessons for today's soldiers. Survival, 50(4), 177-190. doi:10.1080/00396330802329071

Moore, H. (2011). Vietnam War hero offers leadership lessons. Retrieved from https://americanprofile.com/articles/leadership-lessons-list-from -vietnam-veteran

Nauvall, J. (2019). Stoicism: The ultimate guide for beginners to improve selfdiscipline, mental toughness, leadership, wisdom, resilience, inner peace for living a good life, based on the stoics philosophy. Self published by author Jonathan Nauvall.

Poser, J. (2018). No better friend, no worse enemy: The life of General James Mattis. New York, NY: Broadside Books.

Ricks, T. (2017, February 17). The tragedy of James Mattis. Retrieved from https://foreignpolicy.com/2017/02/17/the-tragedy-of-james-mattis 
Sauer, M. (2007, September 27). The revolt of the generals: Generals opposing Iraq war break with military tradition. Global Tribune. Retrieved from https://www.globalresearch.ca/the-revolt-of-the-generals-generals -opposing-iraq-war-break-with-military-tradition/6920

Sellars, J. (2006). Stoicism (Ancient Philosophies). Vol. 1. New York: Routledge. Seneca, L. A. (2004). Letters from a Stoic. New York, NY: Penguin Books.

Seneca, L. A. (2015). Selected dialogues and consolations (P. Anderson, Trans.). Indianapolis, IN: Hackett Publishing.

Sherman, N. (2005). Stoic warriors: The ancient philosophy behind the military mind. New York, NY: Oxford University Press.

Sicard, S. (2017, April 2). 30 Books Mattis thinks every good leader needs to read. Task and Purpose. Retrieved from https://taskandpurpose .com/30-books-mattis-thinks-every-good-leader-needs-read

Stockdale, J. (1993). Courage under fire: Testing Epictetus's doctrines in a laboratory of human behavior. Stanford, CA: Hoover Institution, Stanford University.

Stockdale, J. (1995). Stockdale on Stoicism II: Master of my fate (U.S. Naval Academy). Retrieved from https://www.usna.edu/Ethics/_files/ documents/Stoicism2.pdf

U.S. Air Force. (n.d.). Air Force core values. Retrieved from https://www .airforcemomsbmt.org/AirForceCoreValues.htm

U.S. Army. (n.d.-a). Army core values. Retrieved from https://www.army.mil/ values

U.S. Army. (n.d.-b). Lifestyles: Living the Army values: Ethos. Retrieved from https://www.goarmy.com/soldier-life/being-a-soldier/living-the-army -values.html

U.S. Army. (2011). Warrior ethos. Retrieved from https://www.army.mil/ article/50082/warrior_ethos

U.S. Army Center of Military History. (n.d.). Oaths of enlistment and oaths of office. Retrieved from https://history.army.mil/html/faq/oaths.html

U.S. Coast Guard. (n.d.). "Introduction". Retrieved from https://www .gocoastguard.com/family-and-friends/the-helmsman/introduction

U.S. Government Printing Office. (1958). Code of conduct for members of the armed forces of the United States. Washington, DC. Retrieved from https://www .archives.gov/federal-register/codification/executive-order/10631.html

U.S. Navy. (2009). U.S. Navy core values. Retrieved from https://www.secnav .navy.mil/Ethics/Pages/corevaluescharter.aspx\#: :text=As\%20in\%20 our $\% 20$ past $\% 2$ $\% 20$ we,continue $\% 20$ to $\% 20$ guide $\% 20$ us $\% 20$ today.

van der Hart, O., Nijenhuis, E., \& Steele, K. (2006). The haunted self: Structural dissociation and the treatment of chronic traumatization. New York: W.W. Norton \& Co.

von Steuben, F. (n.d.). A letter on the subject of an established militia and military arrangements: Addressed to the inhabitants of the United States. New York, NY: Sabin Americana. 